\title{
Cap-assisted colonoscopy versus standard colonoscopy: is the cap beneficial? A meta-analysis of randomized controlled trials
}

\author{
Fazia A. Mira, Christine Boumitria, Imran Ashrafa, Michelle L. Matteson-Kome ${ }^{a}$, Douglas L. Nguyen ${ }^{\text {, }}$ \\ Srinivas R. Pulic, Matthew L. Bechtold ${ }^{a}$
}

University of Missouri, Columbia; University of California, Irvine; University of Illinois, Peoria, USA

\section{Abstract}

Departments of a Medicine, University of Missouri, Columbia (Fazia A. Mir, Christine Boumitri, Imran Ashraf, Michelle L. Matteson-Kome, Matthew L. Bechtold); ${ }^{\text {} M e d i c i n e, ~}$ University of California, Irvine (Douglas L. Nguyen); ${ }^{\mathrm{C}}$ Medicine, University of Illinois, Peoria (Srinivas R. Puli), USA

\section{Conflict of Interest: None}

Correspondence to: Matthew L. Bechtold, MD, FACP, FASGE, FACG, AGAF, Division of Gastroenterology and Hepatology, CE405, DC 043.00, University of Missouri Health Sciences Center, Five Hospital Drive, Columbia, MO 65212, USA, e-mail: bechtoldm@health.missouri.edu

Received 28 April 2017; accepted 21 June 2017; published online 24 July 2017

DOI: https://doi.org/10.20524/aog.2017.0180

\section{Introduction}

According to the American Cancer Society, colorectal cancer is one of the three most common neoplasms for both men and women in the United States [1]. Colonoscopy has been widely used as a diagnostic and preventative tool for colon cancer for many years [2]. About 3.3 million colonoscopies are performed every year in the United States [3]. Over half of them are done for the purposes of screening and surveillance [4]. Properly performed colonoscopies are considered safe and effective for the screening and surveillance of colorectal cancer.

At present, colonoscopy is the first-line screening choice for the prevention and diagnosis of colorectal cancer [5], because of its ability to detect polyps and adenomas as well as facilitate 
their removal [6]. However, colonoscopy is not perfect. Cancer, described as interval cancer, may develop after negative screening colonoscopy because of missed lesions [7,8]. In an effort to decrease these interval cancers, many quality parameters have been used to determine the quality of the endoscopist; one of these is the adenoma detection rate (ADR).

The ADR for any endoscopist has an inverse correlation with the development of interval cancers [9]. If the ADR is high, then the development of interval cancers will likely be low in the endoscopist's patient population. With every $1 \%$ increase in ADR, a $3 \%$ decline in interval colon cancer development may be observed [10]. Therefore, the quality of screening colonoscopy is very important. Numerous other quality indicators for colonoscopy have been established, including bowel preparation scoring systems, cecal intubation time, cecal intubation rate, polyp detection rate (PDR), and withdrawal time [11].

Recently, the American Society for Gastrointestinal Endoscopy and the American College of Gastroenterology came forward with guidelines recommending that endoscopists performing screening colonoscopies should have a $90 \%$ cecal intubation rate [11]. This is the same criterion proposed by the United States Multi-Society Task Force on colon cancer [12]. A good quality screening colonoscopy is a prerequisite for optimal patient care and many of the quality indicators described need to be fulfilled for reimbursement [13].

In the literature, adenoma miss rates have been reported to be up to $24 \%$ after a complete colonoscopy $[14,15]$. Advances in colonoscopy techniques to decrease adenoma miss rates include a withdrawal time of greater than $6 \mathrm{~min}$, retroflexion in the right colon, endorings, polyp removal on insertion, endocuff, chromoendoscopy, narrow-band imaging, molecular imaging, enhanced electronic imaging, dynamic positioning of patient, third-eye retroscope, wide-angle colonoscopy, G-eye balloon, and cap-assisted colonoscopy [15-21]. These supplementary tools, offered to increase ADR, come at a cost and may increase procedure time significantly.

Cap-assisted colonoscopy (CAC) is the attachment of a distal transparent cap to the end of the colonoscope to facilitate passage and increase ADR. The distal cap attachment acts to improve ADR by increasing mucosal surface visualization through flattening of haustral folds on withdrawal of the colonoscope [22]. Studies comparing CAC versus standard colonoscopy (SC) without the cap have yielded conflicting results, with some favoring utilization of a cap while others have a negative view of cap use $[23,24]$. Our study aim was to examine the impact of CAC on common quality parameters for colonoscopy, including ADR.

\section{Materials and methods}

A systematic and comprehensive literature search of Scopus, MEDLINE/PubMed, CINAHL, Cochrane databases, and recent abstracts (between 2008 and 2016) from major American meetings (Digestive Disease Week and the American College of Gastroenterology) were searched in November 2016. In addition, the reference lists of all articles were searched. Search terms used were "cap" or "hood" and "colonoscopy". Two reviewers (FM and $\mathrm{CB}$ ) independently reviewed all abstracts returned by the search. A third reviewer (MLB) confirmed these results and mutual agreement was necessary in cases of discrepancy or disagreement. Only randomized controlled trials (RCTs) that involved adult patients and compared the practice of CAC versus SC were included in the analysis. Short caps, with less than $2 \mathrm{~mm}$ of protrusion from the distal tip of the colonoscope, were excluded. A meta-analysis was conducted using calculated pooled estimates of total colonoscopy time, time to cecum, cecal intubation rate, terminal ileum intubation rate, PDR, and ADR. Every outcome was analyzed with Mantel-Haenszel or DerSimonian and Laird models, using the odds ratio (OR) for dichotomous data or the mean difference (MD) for continuous data. The $\mathrm{I}^{2}$ measure of inconsistency was used to assess heterogeneity $\left(\mathrm{P}<0.05\right.$ or $\mathrm{I}^{2}>50 \%$ was considered significant). If statistically significant heterogeneity was observed, a sensitivity analysis was performed and certain studies were removed, leading to heterogeneity. RevMan 5.3 (Review Manager, Version 5.3, Copenhagen: The Nordic Cochrane Centre, The Cochrane Collaboration, 2012) was used for the statistical analysis. Quality assessment of the included studies was performed using the Cochrane Collaboration's tool for assessing risk of bias [25-27]. A GRADE was assigned to each outcome based on the quality of evidence. This GRADE may be very low, low, moderate, or high quality, based on variable quality parameters [25-27].

\section{Results}

A total of 589 potential articles and abstracts were identified, of which 40 appropriate articles were reviewed. Once the comprehensive search had been completed, 23 RCTs were included in the final analysis [22-24,28-47] (Fig. 1). The characteristics of the 23 studies included are summarized in Table 1. These studies included 12,947 patients with mean age ranging from 47-64.6 years. The quality of studies ranged from low, moderate, and high quality (Table 2).

\section{Duration of colonoscopy}

Fifteen studies evaluated time to the cecum for colonoscopy $(\mathrm{n}=7241)$ [23,24,29-32,35-37,39-44]. Mean time to the cecum ranged from 3.3-12.4 min for CAC, and 4-16.8 min for SC. On pooled analysis, a statistically significantly shorter time to the cecum was observed for CAC compared to SC (MD -0.82 min; $95 \%$ confidence interval $[\mathrm{CI}]-1.20$ to $-0.44 ; \mathrm{P}<0.01$ ) (Fig. $2 \mathrm{~A}$ ). Significant heterogeneity was noted on this analysis $\left(\mathrm{I}^{2}=62 \%\right.$, $\mathrm{P}<0.01)$. Based on this heterogeneity, a sensitivity analysis was performed and revealed similar results when two studies were excluded [31,35] with no significant heterogeneity (MD -0.84 min; 95\%CI - 1.15 to $-0.52 ; \mathrm{P}<0.01 ; \mathrm{I}^{2}=34 \%, \mathrm{P}=0.11$ ).

Seven studies evaluated the total time of colonoscopy $(n=2811)$ [29-32,34-36]. Mean total time of colonoscopy 
Table 1 Characteristics of the studies included in the meta-analysis

\begin{tabular}{|c|c|c|c|c|c|c|c|c|c|}
\hline Studies & Site & Year & Type & $\begin{array}{c}\text { Total } \\
\text { sample size }\end{array}$ & Males & Females & CAC & SC & Cap size* \\
\hline Pohl et al [22] & USA & 2015 & Manuscript & 1113 & 709 & 404 & 561 & 552 & $4 \mathrm{~mm}$ \\
\hline Kim et al [28] & South Korea & 2015 & Manuscript & 1023 & 549 & 474 & 515 & 508 & $4 \mathrm{~mm}$ \\
\hline Frieling et al [29] & Germany & 2013 & Manuscript & 504 & 282 & 222 & 252 & 252 & $5-10 \mathrm{~mm}$ \\
\hline Rastogi et al [24] & USA & 2012 & Manuscript & 420 & 398 & 22 & 210 & 210 & $4 \mathrm{~mm}$ \\
\hline de Wijkerslooth et al [23] & Netherlands & 2012 & Manuscript & 1339 & 685 & 654 & 683 & 656 & $4 \mathrm{~mm}$ \\
\hline Park et al [30] & South Korea & 2011 & Manuscript & 329 & 235 & 94 & 166 & 163 & $4 \mathrm{~mm}$ \\
\hline Dai et al [31] & China & 2010 & Manuscript & 250 & 134 & 116 & 121 & 129 & $4 \mathrm{~mm}$ \\
\hline Tee et al [32] & Malaysia & 2010 & Manuscript & 400 & 190 & 210 & 200 & 200 & $4 \mathrm{~mm}$ \\
\hline Takeuchi et al [33] & Japan & 2010 & Manuscript & 274 & 192 & 82 & 141 & 133 & $4 \mathrm{~mm}$ \\
\hline Hewett et al [34] & USA & 2010 & Manuscript & 100 & 57 & 43 & 52 & 48 & $4 \mathrm{~mm}$ \\
\hline Choi et al [35] & South Korea & 2010 & Manuscript & 228 & 108 & 120 & 114 & 114 & $4 \mathrm{~mm}$ \\
\hline Lee et al [36] & China & 2009 & Manuscript & 1000 & 460 & 540 & 499 & 501 & $10 \mathrm{~mm}$ \\
\hline Harada et al [37] & Japan & 2009 & Manuscript & 592 & 391 & 201 & 289 & 303 & $2 \mathrm{~mm}$ \\
\hline Shida et al [38] & Japan & 2008 & Manuscript & 178 & 90 & 88 & 82 & 96 & $4 \mathrm{~mm}$ \\
\hline Horiuchi et al [39] & Japan & 2008 & Manuscript & 835 & 543 & 292 & 424 & 411 & $\leq 7 \mathrm{~mm}$ \\
\hline Kondo et al [40] & Japan & 2007 & Manuscript & 456 & 273 & 183 & 221 & 235 & $4 \mathrm{~mm}$ \\
\hline Matsushita et al [41] & Japan & 1998 & Manuscript & 48 & 15 & 9 & 24 & 24 & $4-9 \mathrm{~mm}$ \\
\hline Tada et al [42] & Japan & 1997 & Manuscript & 140 & 102 & 38 & 70 & 70 & $\leq 6 \mathrm{~mm}$ \\
\hline Othman et al [43] & USA & 2014 & Abstract & 440 & 139 & 301 & 223 & 217 & NS \\
\hline Lee et al [44] & South Korea & 2011 & Abstract & 260 & NA & NA & 127 & 133 & NS \\
\hline Jung et al [45] & South Korea & 2011 & Abstract & 295 & NA & NA & 150 & 145 & NS \\
\hline Sato et al [46] & Japan & 2009 & Abstract & 221 & NA & NA & 110 & 111 & NS \\
\hline Takano et al [47] & Japan & 2008 & Abstract & 2502 & NA & NA & 1287 & 1215 & NS \\
\hline
\end{tabular}

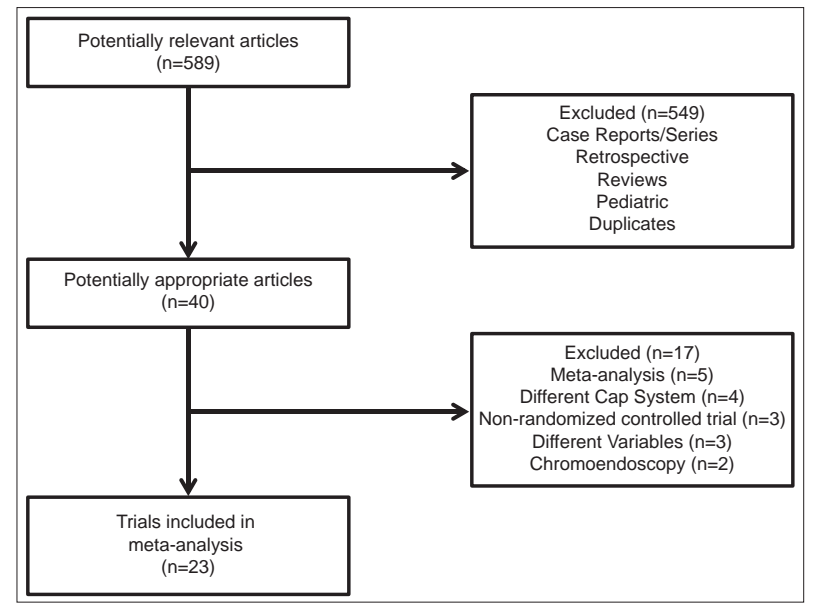

Figure 1 Details of article search and identification

ranged from 13.1-23.2 min for CAC and 13.9-29.2 min for SC. On pooled analysis, a statistically significantly shorter total time of colonoscopy was noted for CAC compared to SC (MD - $1.51 \mathrm{~min} ; 95 \% \mathrm{CI}-2.67$ to -0.34 ; $\mathrm{P}<0.01$ ) (Fig. $2 \mathrm{~B})$.
Significant heterogeneity was noted on this analysis $\left(\mathrm{I}^{2}=86 \%\right.$, $\mathrm{P}<0.01)$. Based on this heterogeneity, a sensitivity analysis was performed and revealed similar results when three studies were excluded $[30,31,34]$ with no significant heterogeneity ( $\mathrm{MD}-1.27 \mathrm{~min} ; 95 \% \mathrm{CI}-2.13$ to $-0.41 ; \mathrm{P}<0.01 ; \mathrm{I}^{2}=27 \%, \mathrm{P}=0.25$ ).

\section{Success of colonoscopy}

The success of colonoscopy was evaluated by cecal intubation and terminal ileum intubation rates. Seventeen studies compared $\mathrm{CAC}$ to $\mathrm{SC}$ for cecal intubation rate $(n=10,904)[22-24,29,32-40,43,45-47]$. In the CAC group, the cecum was intubated in 5344 of 5500 (97.2\%) colonoscopies. In the SC group, the cecum was intubated in 5193 of 5404 (96.1\%) colonoscopies. On pooled analysis, no statistically significant difference was noted between $\mathrm{CAC}$ and $\mathrm{SC}$ with regards to cecal intubation rate (OR 1.32; 95\%CI 0.94-1.87; $\mathrm{P}=0.11$; $\mathrm{I}^{2}=42 \%, \mathrm{P}=0.06$ ) (Fig. $3 \mathrm{~A}$ ).

Seven studies examined terminal ileum intubation rates $(n=4320)[22,24,29,32,36,39,41]$. For CAC, the terminal ileum was intubated in 1821 of 2170 (83.9\%) colonoscopies. For SC, 
Table 2 Assessment of quality of included studies using the Cochrane Collaboration's Risk of Bias Tool

\begin{tabular}{|c|c|c|c|c|c|c|c|c|}
\hline Study & $\begin{array}{l}\text { Random } \\
\text { sequence } \\
\text { generation }\end{array}$ & $\begin{array}{l}\text { Allocation } \\
\text { concealment }\end{array}$ & Blinding & $\begin{array}{l}\text { Blinding } \\
\text { outcome } \\
\text { assessment }\end{array}$ & $\begin{array}{l}\text { Incomplete } \\
\text { outcome } \\
\text { data }\end{array}$ & $\begin{array}{l}\text { Selective } \\
\text { reporting }\end{array}$ & $\begin{array}{l}\text { Other } \\
\text { bias }\end{array}$ & $\begin{array}{l}\text { Quality } \\
\text { assessment }\end{array}$ \\
\hline Pohl et al [22] & Adequate & Adequate & Single & Adequate & None & None & None & High \\
\hline Kim et al [28] & Adequate & Adequate & Single & Adequate & None & None & None & High \\
\hline Frieling et al [29] & Inadequate & Adequate & Single & Adequate & None & None & None & High \\
\hline Rastogi et al [24] & Adequate & Adequate & Single & Adequate & None & None & Mild & Moderate-to-high \\
\hline de Wijkerslooth et al [23] & Adequate & Adequate & Single & Adequate & None & None & None & High \\
\hline Park et al [30] & Adequate & Adequate & Single & Adequate & None & None & None & High \\
\hline Dai et al [31] & None & None & Single & Adequate & None & None & None & Moderate \\
\hline Tee et al [32] & Adequate & Adequate & Single & Adequate & None & None & None & High \\
\hline Takeuchi et al [33] & Adequate & Adequate & Single & Adequate & None & None & None & High \\
\hline Hewett et al [34] & Adequate & Adequate & Single & Adequate & None & None & None & High \\
\hline Choi et al [35] & None & None & Single & Adequate & None & None & None & Low-to-moderate \\
\hline Lee et al [36] & Adequate & Adequate & Single & Adequate & None & None & None & High \\
\hline Harada et al [37] & Adequate & Adequate & Single & Adequate & None & None & None & High \\
\hline Shida et al [38] & None & None & Single & Adequate & None & None & None & Moderate \\
\hline Horiuchi et al [39] & Adequate & Adequate & Single & Adequate & None & None & None & High \\
\hline Kondo et al [40] & Adequate & Inadequate & Single & Adequate & None & None & None & Moderate-to-high \\
\hline Matsushita et al [41] & Adequate & Adequate & Single & Adequate & None & None & None & High \\
\hline Tada et al [42] & None & None & Single & Adequate & None & None & None & Moderate \\
\hline Othman et al [43] & None & None & Unknown & None & None & None & None & Low \\
\hline Lee et al [44] & None & None & Unknown & None & None & None & None & Low \\
\hline Jung et al [45] & None & None & Unknown & None & None & None & None & Low \\
\hline Sato et al [46] & None & None & Unknown & None & None & None & None & Low \\
\hline Takano et al [47] & None & None & Unknown & None & None & None & None & Low \\
\hline
\end{tabular}

the terminal ileum was intubated in 1787 of 2150 (83.1\%) colonoscopies. On pooled analysis, no statistically significant difference was noted between $\mathrm{CAC}$ and SC as regards terminal ileum intubation rate (OR 1.08; 95\%CI 0.70-1.66; $\mathrm{P}=0.73 ; \mathrm{I}^{2}=80 \%, \mathrm{P}<0.01$ ) (Fig. $3 \mathrm{~B}$ ). Because of the significant heterogeneity, a sensitivity analysis was performed and revealed similar results when one study was excluded [22] with no significant heterogeneity (OR 1.28; 95\%CI 0.99-1.67; $\mathrm{P}=0.06 ; \mathrm{I}^{2}=44 \%, \mathrm{P}=0.11$ ).

\section{PDR and ADR}

PDR and ADR were examined in many of the RCTs. Eleven studies evaluated PDR between CAC and SC $(n=6916)[28,29,31-33,35,37,40,43,44,47]$. With CAC, at least one polyp was detected during colonoscopy in 1547 of 3482 colonoscopies, yielding a PDR of $44.4 \%$. With SC, at least one polyp was detected in 1390 of 3434 colonoscopies, yielding a PDR of $40.5 \%$. On pooled analysis, CAC demonstrated significantly more polyps than SC (OR 1.17; 95\%CI 1.06-1.29; $\mathrm{P}<0.01 ; \mathrm{I}^{2}=36 \%, \mathrm{P}=0.11$ ) (Fig. 4).
Ten studies compared ADR between CAC and SC $(n=7176)[22-24,28,29,33,35,36,39,43]$. With CAC, at least one adenoma was detected during colonoscopy in 1258 of 3622 colonoscopies, giving an ADR of $34.7 \%$. With SC, at least one adenoma was detected in 1169 of 3554 colonoscopies, giving a PDR of $32.9 \%$. On pooled analysis, no difference was observed between CAC and SC concerning ADR (OR 1.11; 95\%CI 0.951.3; $\mathrm{P}=0.2 ; \mathrm{I}^{2}=56 \%, \mathrm{P}=0.02$ ) (Fig. 5). However, because of the statistically significant heterogeneity, a sensitivity analysis was performed and revealed contrary results when one study was excluded [36] with no significant heterogeneity (OR 1.17; 95\%CI 1.04-1.33; $\left.\mathrm{P}=0.01 ; \mathrm{I}^{2}=19 \%, \mathrm{P}=0.27\right)$. This study [36] was removed as it described the CAC group receiving significant lower bowel preparation scores than the SC group, likely to have affected ADR.

\section{Discussion}

Acceptable ADRs of endoscopists result in safe recommendation of screening and surveillance intervals for 


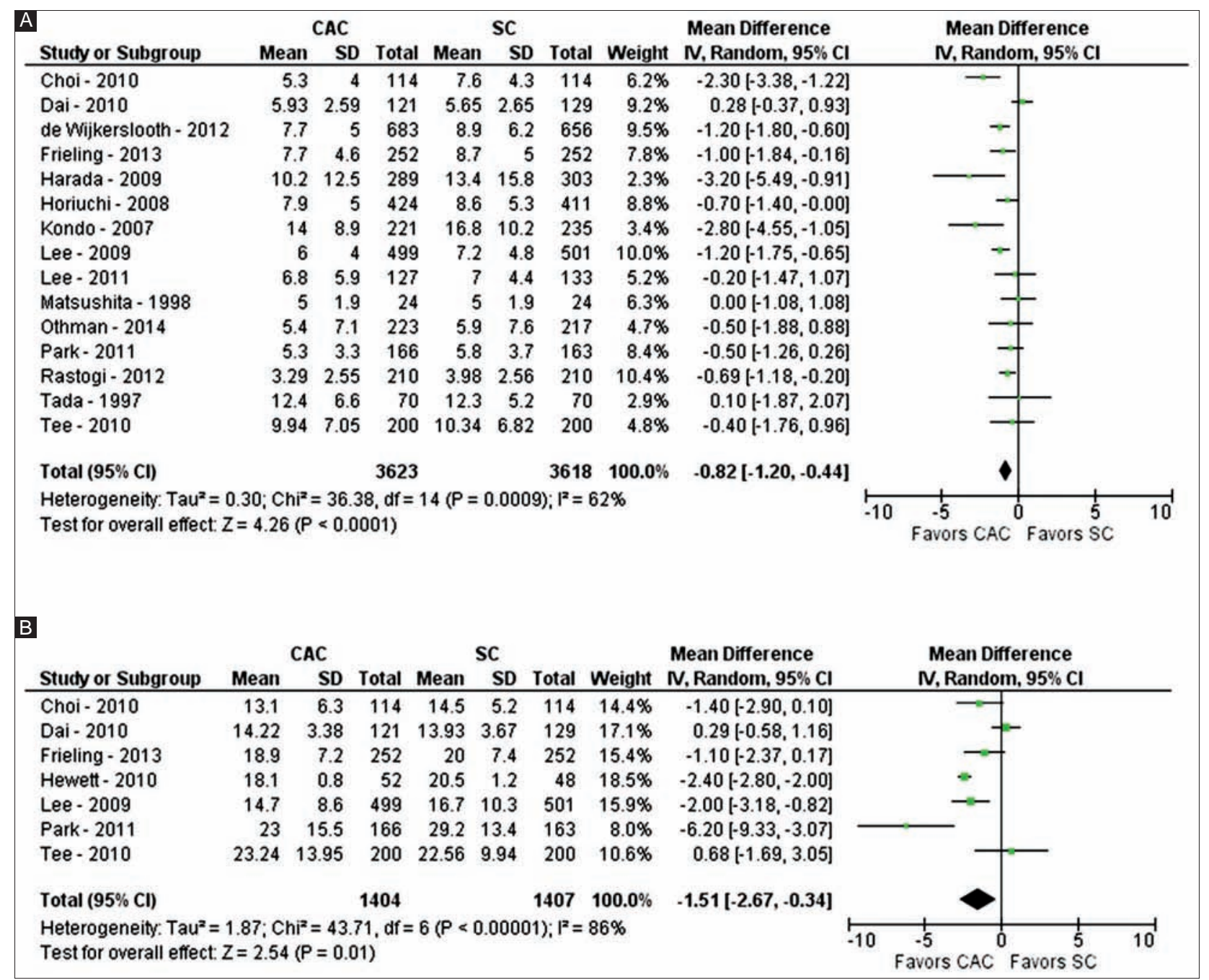

Figure 2 Forest plot showing the comparison between cap-assisted colonoscopy and standard colonoscopy for procedure times, including time to cecum (A) and total time of procedure (B)

colonoscopies [48]. To achieve high ADRs, the colon should be inspected by performing complete insufflation and looking behind each fold [49]. A longer withdrawal time has also been reported to aid in achieving a high ADR [50]. Furthermore, CAC has been evaluated to improve ADR.

Attachment of a cap can aid the endoscopist but also hinder the colonoscopy. On the one hand, the cap can depress the haustral folds and keep the tip of the colonoscope a short distance away from the colonic mucosa [24,34], thereby providing a 360-degree view of the colonic lumen and significantly decreasing the surface area of the colon left unexamined [51]. However, if bowel preparation is average, fecal material can get lodged in the cap and impede visualization. The cap length can also be a factor; if a short cap (2-4 $\mathrm{mm})$ is used then polyp detection may be increased, but longer caps $(7-11 \mathrm{~mm})$ have been shown to shorten the time to cecal intubation. CAC has been hypothesized to shorten the time to cecal intubation by prevention of red-out, better separation of colonic folds and better orientation of the lumen.
It can also aid in the navigation of swollen sigmoid areas with diverticulosis in the elderly, thereby decreasing cecal intubation time in difficult colonoscopies.

In a randomized trial by Pohl et al, CAC resulted in a faster cecal intubation time $(4.9$ vs. $5.8 \mathrm{~min}$; $\mathrm{P}<0.001)$ but there was no increase in ADR [22]. Lee et al reported that CAC achieved a higher cecal intubation rate in patients with previously failed colonoscopies when compared with SC (67\% vs. $21 \% ; \mathrm{P}=0.003$ ) [36]. Postulated mechanisms of shortening cecal intubation time and achieving a successful colonoscopy in difficult cases include the utilization of less air during the colonoscopy by using a cap and the ability to "hook" the colonoscope in folds, with subsequent loop reduction [24]. Harada et al conducted a prospective randomized study comparing the cecal intubation time between CAC and SC [37]. This trial showed a significant impact for the more experienced endoscopist, with mean cecal intubation time with the cap being $10.2 \pm 12.5 \mathrm{~min}$ compared to $13.4 \pm 15.8 \mathrm{~min}$ for $\mathrm{SC}(\mathrm{P}=0.024)$. Lee et $a l$, in their randomized trial, 


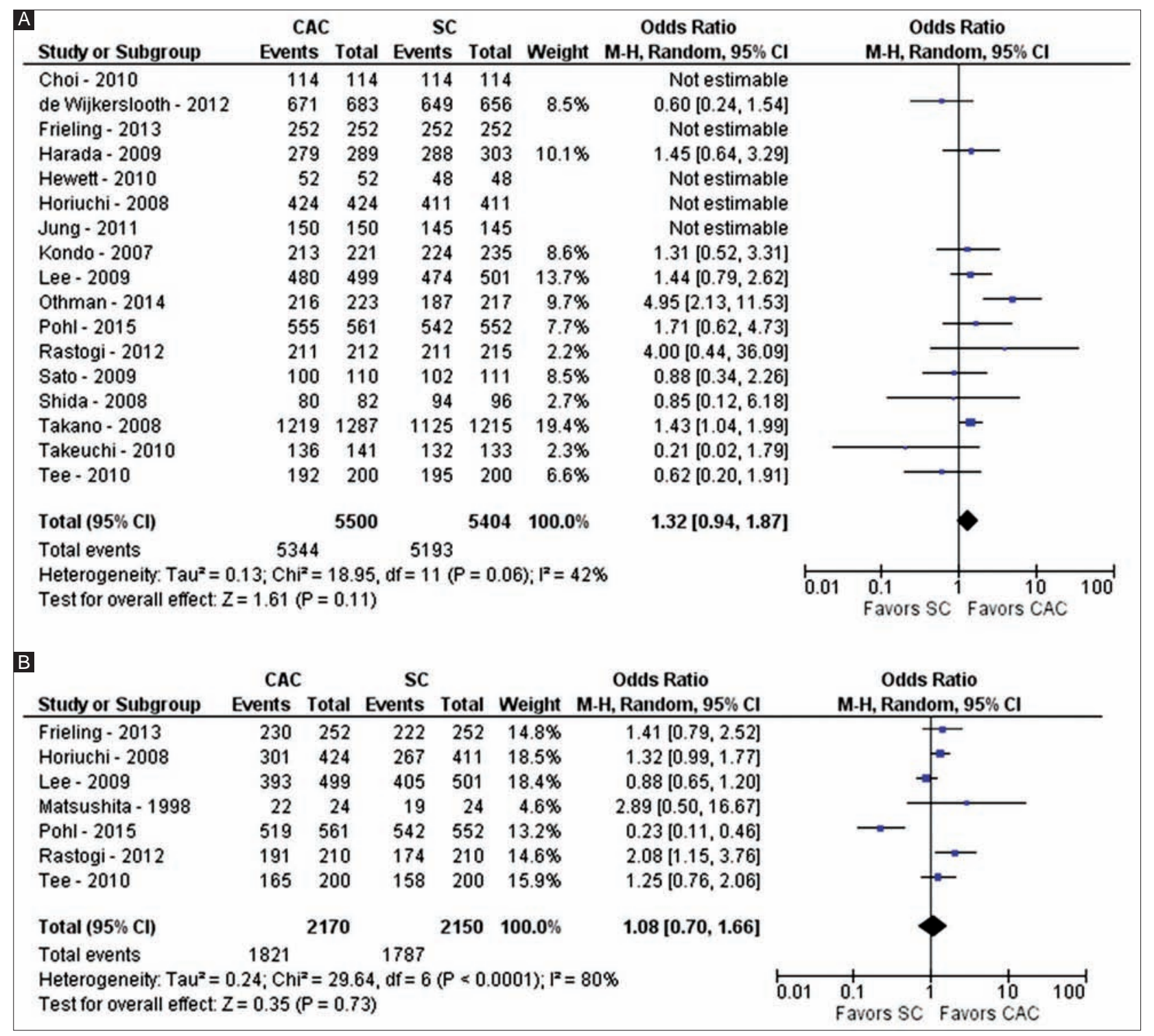

Figure 3 Forest plot showing the comparison between cap-assisted colonoscopy and standard colonoscopy for success of intubation of the cecum (A) and terminal ileum (B)

demonstrated cecal intubation time shortening by $1.2 \mathrm{~min}$ with the use of a cap [36]. Similarly, Rastogi et al showed that the mean time to reach the cecum with the aid of a cap was $3.29 \mathrm{~min}$ versus $3.98 \mathrm{~min}$ with SC $(\mathrm{P}<0.001)$ [24]. Another large randomized trial by de Wijkerslooth et al showed a lowered cecal intubation time with CAC compared to SC (7.7 \pm 5.0 vs. $8.9 \pm 6.2 \mathrm{~min} ; \mathrm{P}<0.001$ ) [23].

Multiple meta-analyses have been performed on this subject over the past six years [51-57]. Morgan et al, in 2011, found only marginally improved cecal intubation rates, but only included five RCTs [52]. In 2012, Westwood et al concluded that PDR improved using transparent caps, but cecal intubation time did not [51]. In 2012, Ng et al found only marginal improvement in cecal intubation times and PDR; however, total colonoscopy time did not differ between the two groups [53]. He et al, in 2013, demonstrated that a transparent cap helps trainees but makes little difference to cecal intubation times for skilled endoscopists [54]. Morgan et al, in 2013, found that in 14 RCTs cecal intubation time was significantly improved but polyp detection was not [55,56]. Similarly, in 2014, Omata et al found no improvement in ADR with a transparent cap [57]. Given the varied results concerning cecal intubation times and ADR, this meta-analysis was performed, representing the largest to-date.

This meta-analysis shows that the implementation of a transparent cap with colonoscopy results in a significant reduction in time to the cecum and total time of colonoscopy, while improving PDR. However, cecal and terminal ileum intubation success was similar between the two groups. On pooled analysis of all available studies, ADR did not seem to be significantly improved. However, in a sensitivity analysis, ADR appeared to be better with CAC. The reasoning is that one study [36] may be inducing significant heterogeneity 


\begin{tabular}{|c|c|c|c|c|c|c|c|c|c|c|}
\hline Study or Subgroup & \multicolumn{2}{|c|}{ CAC } & $\begin{array}{r}\mathrm{SC} \\
\text { Events } \\
\end{array}$ & Total & Weight & $\begin{array}{c}\text { Odds Ratio } \\
\text { M-H, Fixed, } 95 \% \mathrm{Cl}\end{array}$ & \multicolumn{4}{|c|}{$\begin{array}{c}\text { Odds Ratio } \\
\text { M-H, Fixed, } 95 \% \mathrm{Cl}\end{array}$} \\
\hline Choi - 2010 & 44 & 114 & 38 & 114 & $3.1 \%$ & $1.26[0.73,2.16]$ & & & - & \\
\hline Dai- 2010 & 19 & 121 & 19 & 129 & $2.0 \%$ & $1.08[0.54,2.15]$ & & & - & \\
\hline Frieling - 2013 & 80 & 252 & 99 & 252 & $8.9 \%$ & $0.72[0.50,1.04]$ & & & & \\
\hline Harada- 2009 & 120 & 289 & 122 & 303 & $9.2 \%$ & $1.05[0.76,1.46]$ & & & - & \\
\hline Kim- 2015 & 250 & 515 & 207 & 508 & $14.1 \%$ & $1.37[1.07,1.76]$ & & & - & \\
\hline Kondo- 2007 & 109 & 221 & 92 & 235 & $6.0 \%$ & $1.51[1.04,2.19]$ & & & - & \\
\hline Lee - 2011 & 72 & 127 & 59 & 133 & $3.3 \%$ & $1.64[1.01,2.68]$ & & & 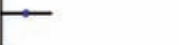 & \\
\hline Othman - 2014 & 87 & 223 & 92 & 217 & $7.5 \%$ & $0.87[0.59,1.27]$ & & & L & \\
\hline Takano - 2008 & 605 & 1287 & 518 & 1215 & $37.2 \%$ & $1.19[1.02,1.40]$ & & & 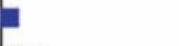 & \\
\hline Takeuchi - 2010 & 98 & 141 & 83 & 133 & $3.4 \%$ & $1.37[0.83,2.27]$ & & & & \\
\hline Tee - 2010 & 63 & 192 & 61 & 195 & $5.4 \%$ & $1.07[0.70,1.64]$ & & & - & \\
\hline Total $(95 \% \mathrm{Cl})$ & & 3482 & & 3434 & $100.0 \%$ & $1.17[1.06,1.29]$ & & & 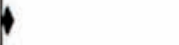 & \\
\hline Total events & 1547 & & 1390 & & & & & & & \\
\hline $\begin{array}{l}\text { Heterogeneity: Chi } \\
\text { Test for overall effec }\end{array}$ & $\begin{array}{l}15.52, \mathrm{df} \\
Z=3.22\end{array}$ & $\begin{array}{l}=10(P \\
(P=0.0\end{array}$ & $\begin{array}{l}=0.11) ; \\
01)\end{array}$ & $F^{2}=38$ & & & 0.01 & $\begin{array}{l}0.1 \\
\text { Favors SC }\end{array}$ & $\begin{array}{c}10 \\
\text { Favors CAC }\end{array}$ & 100 \\
\hline
\end{tabular}

Figure 4 Forest plot showing the comparison between cap-assisted colonoscopy and standard colonoscopy for polyp detection rate

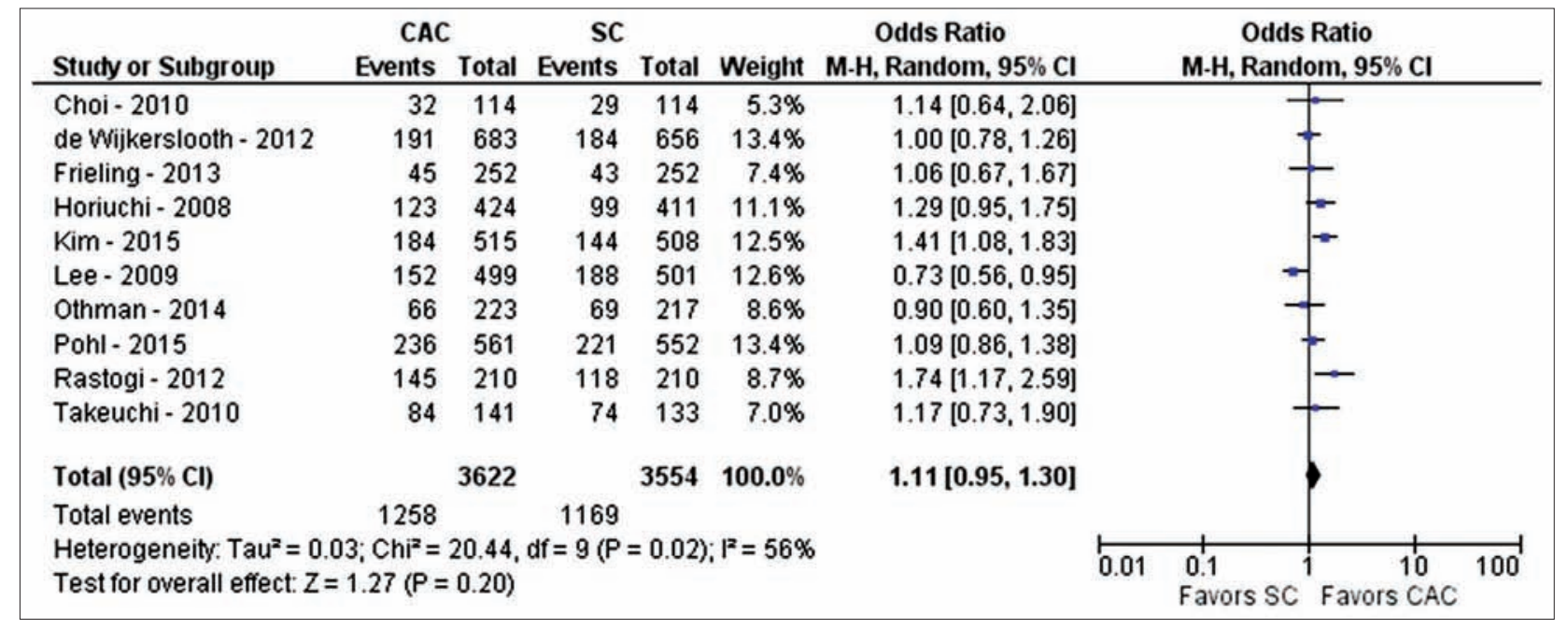

Figure 5 Forest plot showing the comparison between cap-assisted colonoscopy and standard colonoscopy for adenoma detection rate

because the cap-assisted group experienced much poorer bowel preparations, which would be likely to impact the overall results for ADR. When this study was removed from the analysis, ADR appeared to be improved with CAC. Thus, ADR is likely to be improved with CAC but more studies may be necessary to reduce heterogeneity while including all studies.

With any meta-analysis, the strengths and limitations need to be mentioned. In this analysis, the strengths include the inclusion of only RCTs, large number of patients from various countries around the world, multiple clinical-based outcomes, sensitivity analysis on all outcomes with significant heterogeneity, and the largest meta-analysis to date on the subject of CAC. However, limitations also exist. First, few of the outcomes had statistically significant heterogeneity. In an effort to reduce the impact on results, a random effects model was utilized. In addition, a sensitivity analysis was performed that removed possible offending studies and evaluated the data, showing that most results were similar with no heterogeneity for all outcomes, the exception being ADR. When all studies were included, ADR demonstrated no difference between CAC and SC. However, on sensitivity analysis, the removal of just one study [36] yielded superior ADR results associated with CAC. Given this result, ADR may be, and probably is improved with CAC, but further studies will need to be performed to fully assess this outcome. Furthermore, given the possible impact of bowel preparation, with the possibility of stool in the cap, other studies have suggested that combining CAC with a second method of water exchange significantly improves ADR; however, more trials are needed to fully evaluate adding a second method $[58,59]$. Second, not all RCTs were blinded to the endoscopist. This may lead to inherent bias throughout the analysis. Given that there is really no conceivable way to blind the endoscopist with CAC studies, this possible bias must be acknowledged. Third, the endoscopists' experience was not 


\section{Summary Box}

\section{What is already known:}

- The quality of colonoscopy is very important, assessed in terms of quality indicators such as adenoma detection rate

- Many techniques have been studied to improve quality outcomes in colonoscopy, including the use of a transparent cap or hood on the distal end of the colonoscope

- The use of a transparent cap or hood remains controversial

\section{What the new findings are:}

- A transparent cap or hood on the colonoscope improves polyp detection rate while reducing procedure times

- Adenoma detection rate is likely to improve in cap-assisted colonoscopy, but further studies are required to confirm this

uniform in the trials being compared. Outcome parameters may be influenced by experience of the endoscopist. Fourth, cap sizes varied across the study. Given this variation, short caps, with less than $2 \mathrm{~mm}$ of protrusion from the distal tip of the colonoscope, were excluded in an attempt to remove inconsistencies from the pooled data. Finally, this study does not evaluate the impact of CAC on endoscopists whose ADR is already high. It is unclear whether the use of a transparent cap will improve ADR and other outcome parameters for those who are already successful in terms of those parameters. Further studies are required to fully assess the impact of CAC, comparing the less-experienced and the more-experienced endoscopist.

In conclusion, CAC appears to be beneficial in reducing procedure time and improving PDR. CAC is also likely to improve ADR but more studies are required to fully assess its impact on ADR. Based on this analysis, CAC is a viable modality for use in screening colonoscopy.

\section{References}

1. American Cancer Society. Cancer Statistics 2015. http://www. cancer.org/research/cancerfactsstatistics/cancerfactsfigures2015/.

2. Bechtold ML, Choudhary A. Bowel preparation prior to colonoscopy: a continual search for excellence. World $J$ Gastroenterol 2013;19:155-157.

3. Peery AF, Dellon ES, Lund J, et al. Burden of gastrointestinal disease in the United States: 2012 update. Gastroenterology 2012;143:11791187.e1-3.

4. Centers for Disease Control and Prevention. Vital signs: colorectal cancer screening test use-United States, 2012. MMWR Morb Mortal Wkly Rep 2013;62:881-888.

5. Zauber AG, Lansdorp-Vogelaar I, Knudsen AB, Wilschut J, van Ballegooijen M, Kuntz KM. Evaluating test strategies for colorectal cancer screening: a decision analysis for the U.S. Preventive Services Task Force. Ann Intern Med 2008;149:659-669.

6. Winawer SJ, Zauber AG, Ho MN, et al. Prevention of colorectal cancer by colonoscopic polypectomy. The National Polyp Study Workgroup. N Engl J Med 1993;329:1977-1981.

7. Singh $H$, Nugent $Z$, Demers AA, Bernstein CN. Rate and predictors of early/missed colorectal cancers after colonoscopy in Manitoba: a population-based study. Am J Gastroenterol 2010;105:2588-2596.

8. Haug U, Regula J. Interval cancer: nightmare of colonoscopists. Gut 2014;63:865-866.

9. Corley DA, Jensen CD, Marks AR, et al. Adenoma detection rate and risk of colorectal cancer and death. $N$ Engl J Med 2014;370:1298-1306.

10. Kaminski MF, Regula J, Kraszewska E, et al. Quality indicators for colonoscopy and the risk of interval cancer. $N$ Engl J Med 2010;362:1795-1803.

11. Rex DK, Schoenfeld PS, Cohen J, et al. Quality indicators for colonoscopy. Gastrointest Endosc 2015;81:31-53.

12. Rex DK, Bond JH, Winawer S, et al; U.S. Multi-Society Task Force on Colorectal Cancer. Quality in the technical performance of colonoscopy and the continuous quality improvement process for colonoscopy: recommendations of the U.S. Multi-Society Task Force on Colorectal Cancer. Am J Gastroenterol 2002;97:1296-1308.

13. Villa NA, Pannala R, Pasha SF, Leighton JA. Alternatives to Incomplete Colonoscopy. Curr Gastroenterol Rep 2015;17:43.

14. Rex DK, Cutler CS, Lemmel GT, et al. Colonoscopic miss rates of adenomas determined by back-to-back colonoscopies. Gastroenterology 1997;112:24-28.

15. Ket SN, Bird-Lieberman E, East JE. Electronic imaging to enhance lesion detection at colonoscopy. Gastrointest Endosc Clin N Am 2015;25:227-242.

16. Moons LM, Gralnek IM, Siersema PD. Techniques and technologies to maximize mucosal exposure. Gastrointest Endosc Clin N Am 2015;25:199-210.

17. Sanaka MR, Parsi MA, Burke CA, et al. Adenoma detection at colonoscopy by polypectomy in withdrawal only versus both insertion and withdrawal: a randomized controlled trial. Surg Endosc 2015;29:692-699.

18. East JE, Bassett P, Arebi N, Thomas-Gibson S, Guenther T, Saunders BP. Dynamic patient position changes during colonoscope withdrawal increase adenoma detection: a randomized, crossover trial. Gastrointest Endosc 2011;73:456-463.

19. Kushnir VM, Oh YS, Hollander T, et al. Impact of retroflexion vs. second forward view examination of the right colon on adenoma detection: a comparison study. Am J Gastroenterol 2015;110:415-422.

20. Triadafilopoulos G, Watts HD, Higgins J, Van Dam J. A novel retrograde-viewing auxiliary imaging device (Third Eye Retroscope) improves the detection of simulated polyps in anatomic models of the colon. Gastrointest Endosc 2007;65:139-144.

21. Gralnek IM, Siersema PD, Halpern Z, et al. Standard forwardviewing colonoscopy versus full-spectrum endoscopy: an international, multicentre, randomised, tandem colonoscopy trial. Lancet Oncol 2014;15:353-360.

22. Pohl H, Bensen SP, Toor A, et al. Cap-assisted colonoscopy and detection of Adenomatous Polyps (CAP) study: a randomized trial. Endoscopy 2015;47:891-897.

23. de Wijkerslooth TR, Stoop EM, Bossuyt PM, et al. Adenoma detection with cap-assisted colonoscopy versus regular colonoscopy: a randomised controlled trial. Gut 2012;61:1426-1434.

24. Rastogi A, Bansal A, Rao DS, et al. Higher adenoma detection rates 
with cap-assisted colonoscopy: a randomised controlled trial. Gut 2012;61:402-408.

25. Higgins JPT, Green S. Cochrane handbook for systematic reviews of interventions. The Cochrane Collaboration 2011. http:// handbook.cochrane.org/.

26. Guyatt GH, Oxman AD, Vist GE, et al; GRADE Working Group. GRADE: an emerging consensus on rating quality of evidence and strength of recommendations. BMJ 2008;336:924-926.

27. GRADE working group. Criteria for applying or using GRADE. http://www.gradeworkinggroup.org/.

28. Kim DJ, Kim HW, Park SB, et al. Efficacy of cap-assisted colonoscopy according to lesion location and endoscopist training level. World J Gastroenterol 2015;21:6261-6270.

29. Frieling T, Neuhaus F, Kuhlbusch-Zicklam R, et al. Prospective and randomized study to evaluate the clinical impact of cap assisted colonoscopy (CAC). Z Gastroenterol 2013;51:1383-1388.

30. Park SY, Kim HS, Yoon KW, et al. Usefulness of cap-assisted colonoscopy during colonoscopic EMR: a randomized, controlled trial. Gastrointest Endosc 2011;74:869-875.

31. Dai J, Feng N, Lu H, Li XB, Yang CH, Ge ZZ. Transparent cap improves patients' tolerance of colonoscopy and shortens examination time by inexperienced endoscopists. J Dig Dis 2010;11:364-368.

32. Tee HP, Corte C, Al-Ghamdi $\mathrm{H}$, et al. Prospective randomized controlled trial evaluating cap-assisted colonoscopy vs standard colonoscopy. World J Gastroenterol 2010;16:3905-3910.

33. Takeuchi Y, Inoue $\mathrm{T}$, Hanaoka $\mathrm{N}$, et al. Autofluorescence imaging with a transparent hood for detection of colorectal neoplasms: a prospective, randomized trial. Gastrointest Endosc 2010;72:1006-1013.

34. Hewett DG, Rex DK. Cap-fitted colonoscopy: a randomized, tandem colonoscopy study of adenoma miss rates. Gastrointest Endosc 2010;72:775-781.

35. Choi DH, Shin HK, Lee YC, et al. Efficacy of transparent capattached colonoscopy: does it improve the quality of colonoscopy? J Korean Soc Coloproctol 2010;26:116-122.

36. Lee YT, Lai LH, Hui AJ, et al. Efficacy of cap-assisted colonoscopy in comparison with regular colonoscopy: a randomized controlled trial. Am J Gastroenterol 2009;104:41-46.

37. Harada Y, Hirasawa D, Fujita N, et al. Impact of a transparent hood on the performance of total colonoscopy: a randomized controlled trial. Gastrointest Endosc 2009;69:637-644.

38. Shida T, Katsuura Y, Teramoto O, et al. Transparent hood attached to the colonoscope: does it really work for all types of colonoscopes? Surg Endosc 2008;22:2654-2658.

39. Horiuchi A, Nakayama Y. Improved colorectal adenoma detection with a transparent retractable extension device. Am J Gastroenterol 2008;103:341-345.

40. Kondo S, Yamaji Y, Watabe H, et al. A randomized controlled trial evaluating the usefulness of a transparent hood attached to the tip of the colonoscope. Am J Gastroenterol 2007;102:75-81.

41. Matsushita M, Hajiro K, Okazaki K, Takakuwa H, Tominaga M. Efficacy of total colonoscopy with a transparent cap in comparison with colonoscopy without the cap. Endoscopy 1998;30:444-447.

42. Tada M, Inoue H, Yabata E, Okabe S, Endo M. Feasibility of the transparent cap-fitted colonoscope for screening and mucosal resection. Dis Colon Rectum 1997;40:618-621.

43. Othman MO, Eloliby M, Davis BR, et al. Cap-assisted colonoscopy
(CAC) is associated with increased detection of advanced adenoma and total number of polyps per patient in a randomized controlled trial in predominately Hispanic population. Gastrointest Endosc 2014;79:AB555. (abstract)

44. Lee JS, Choi SH, Choi SW, Park HS, Kwak SD, Hwang SY. Efficacy of hood-cap associated colonoscopy: comparison with regular colonoscopy, prospective study. Gastrointest Endosc 2011;73:AB410. (abstract)

45. Jung SH, Park SJ, Park MI, Moon W, Kim HH. Efficacy of transparent cap-fitted colonoscopy in cecal intubation time and detection of lesions compared with non-cap fitted colonoscopy. J Gastroenterol Hepatol 2011;26:59-60. (abstract)

46. Sato K, Hirahata K, Furuhata T, Kakemura T, Fujinuma S, Maetani I. Efficacy of obligue transparent cap with colonscope for trainees analyzed with magnetic endoscope imaging (MEI): a preliminary report. Gastrointest Endosc 2009;69:AB120. (abstract)

47. Takano N, Yamaji Y, Kajiwara H, et al. A randomized controlled trial of the usefulness of cap-fitted colonoscopy on the polyp detection. Gastrointest Endosc 2008;67:AB303. (abstract)

48. Rex DK, Schoenfeld PS, Cohen J, et al. Quality indicators for colonoscopy. Am J Gastroenterol 2015;110:72-90.

49. Rex DK. Colonoscopic withdrawal technique is associated with adenoma miss rates. Gastrointest Endosc 2000;51:33-36.

50. Vavricka SR, Sulz MC, Degen L, et al. Monitoring colonoscopy withdrawal time significantly improves the adenoma detection rate and the performance of endoscopists. Endoscopy 2016;48:256-262.

51. Westwood DA, Alexakis N, Connor SJ. Transparent cap-assisted colonoscopy versus standard adult colonoscopy: a systematic review and meta-analysis. Dis Colon Rectum 2012;55:218-225.

52. Transparent Morgan J, Thomas K, Lee-Robichaud H, Nelson RL. Transparent cap colonoscopy versus standard colonoscopy for investigation of gastrointestinal tract conditions. Cochrane Database Syst Rev 2011;(2):CD008211.

53. Ng SC, Tsoi KK, Hirai HW, et al. The efficacy of cap-assisted colonoscopy in polyp detection and cecal intubation: a metaanalysis of randomized controlled trials. Am J Gastroenterol 2012;107:1165-1173.

54. He Q, Li JD, An SL, et al. Cap-assisted colonoscopy versus conventional colonoscopy: systematic review and meta-analysis. Int J Colorectal Dis 2013;28:279-281.

55. Morgan JL, Thomas K, Braungart S, Nelson RL. Transparent cap colonoscopy versus standard colonoscopy: a systematic review and meta-analysis. Tech Coloproctol 2013;17:353-360.

56. Morgan J, Thomas K, Lee-Robichaud H, Nelson RL, Braungart S. Transparent cap colonoscopy versus standard colonoscopy to improve caecal intubation. Cochrane Database Syst Rev 2012;12:CD008211.

57. Omata F, Ohde S, Deshpande GA, Kobayashi D, Masuda K, Fukui T. Image-enhanced, chromo, and cap-assisted colonoscopy for improving adenoma/neoplasia detection rate: a systematic review and meta-analysis. Scand J Gastroenterol 2014;49:222-237.

58. Yen AW, Leung JW, Leung FW. A new method for screening and surveillance colonoscopy: Combined water-exchange and capassisted colonoscopy. J Interv Gastroenterol 2012;2:114-119.

59. Yen AW, Leung JW, Leung FW. A novel method with significant impact on adenoma detection: combined water-exchange and capassisted colonoscopy. Gastrointest Endosc 2013;77:944-948. 